\title{
Field measurements and numerical modeling for the run-up heights and inundation distances of the 2011 Tohoku-oki tsunami at Sendai Plain, Japan
}

\author{
Kazuhisa Goto $^{1}$, Koji Fujima ${ }^{2}$, Daisuke Sugawara ${ }^{3}$, Shigehiro Fujino ${ }^{4}$, Kentaro Imai $^{3}$, \\ Ryouta Tsudaka ${ }^{2}$, Tomoya Abe ${ }^{5}$, and Tsuyoshi Haraguchi ${ }^{6}$ \\ ${ }^{1}$ Planetary Exploration Research Center, Chiba Institute of Technology, 2-17-1 Tsudanuma, Narashino 275-0016, Japan \\ ${ }^{2}$ Department of Civil and Environmental Engineering, National Defense Academy of Japan, \\ 1-10-20 Hashirimizu, Yokosuka, Kanagawa 239-8686, Japan \\ ${ }^{3}$ International Research Institute of Disaster Science, Tohoku University, Aoba 06-6-11, Aramaki, Sendai 980-8579, Japan \\ ${ }^{4}$ Graduate School of Life and Environmental Sciences, University of Tsukuba, 1-1-1 Tennodai, Tsukuba 305-8572, Japan \\ ${ }^{5}$ Graduate School of Environmental Studies, Nagoya University, Nagoya 464-8601, Japan \\ ${ }^{6}$ Graduate School of Sciences, Osaka City University, 3-3-138 Sugimoto, Sumiyoshi-ku, Osaka 558-8585, Japan
}

(Received December 28, 2011; Revised February 21, 2012; Accepted February 23, 2012; Online published January 28, 2013)

\begin{abstract}
We conducted an urgent field survey at the Sendai Plain to measure the run-up heights and inundation distances of the 2011 Tohoku-oki tsunami. We used GPS measurements because of the remarkably long inundation distances (ca. $5.4 \mathrm{~km}$ ). We established an accurate measurement scheme using the far electric reference points (about $350 \mathrm{~km}$ ). Using this method, we quickly measured 69 run-up heights within 3 days. The tsunami run-up heights and inundation distances varied mainly according to the local topography, ranging from $9.6 \mathrm{~m}$ at $0.4 \mathrm{~km}$ to $0.2 \mathrm{~m}$ at $5.4 \mathrm{~km}$, respectively. Furthermore, artificial structures and topography played an important role in constraining the inundation limit. Our observations are important for future analyses using aerial and satellite imagery and numerical modeling in the area because the maximum inundation area might be underestimated in the images as a result of the subtle traces of the tsunami inundation, which were difficult to identify in the field. However, results show that numerical modeling might not reproduce minor inundation beyond the highway without sufficiently high-resolution topographic data because data for the modeling are usually rough, and the highway, small channels, and street gutters, which played an important role in local inundation, are too small a resolution to be recognized in the model.
\end{abstract}

Key words: The 2011 Tohoku-oki tsunami, run-up height, Sendai Plain.

\section{Introduction}

An earthquake of magnitude 9.0 occurred off the Pacific coast of Tohoku, Japan on March 11, 2011 (e.g. Hirose et al., 2011). Soon thereafter, a large tsunami (designated hereinafter as the 2011 Tohoku-oki tsunami) struck the Pacific coast of eastern Japan (e.g. Fujii et al., 2011; Hayashi et al., 2011; Maeda et al., 2011; Mori et al., 2011). After late March, the joint survey group conducted many field surveys to measure the run-up height, flow depth (= inundation depth), and inundation area of the tsunami along the Pacific coast of eastern Japan. More than 5,000 data points have been collected (The 2011 Tohoku Earthquake Tsunami Joint Survey Group (TETJSG), 2011). Such extensive research clarified that the maximum run-up height of the tsunami (ca. $40 \mathrm{~m}$ ) is the largest value among all Japanese recorded tsunami that have been documented during its history (TETJSG, 2011).

The 2011 Tohoku-oki tsunami is also characterized by its remarkably long inundation distance, especially at the

Copyright (c) The Society of Geomagnetism and Earth, Planetary and Space Sciences (SGEPSS); The Seismological Society of Japan; The Volcanological Society of Japan; The Geodetic Society of Japan; The Japanese Society for Planetary Sciences; TERRAPUB.

doi:10.5047/eps. 2012.02.007
Sendai Plain (Fig. 1). In fact, tsunami inundation of up to $5 \mathrm{~km}$ was observed soon after the tsunami based on analyses of aerial photographs and satellite images (e.g. Geospatial Information Authority of Japan (GSI), 2011). Given such a great inundation distance, several difficulties exist for measuring the run-up heights during the field survey soon after the tsunami because: (1) the tsunami traces are subtle near the inundation limit because of sufficient decay of the tsunami energy and an urgent field survey is necessary before such subtle traces disappear, but (2) it is technically difficult to measure many run-up height data quickly using standard measurement methods by levels or total stations because such measurements take a long time for quantitative data collection.

To overcome these problems, we conducted an urgent field survey in early April, 2011, particularly addressing the measurement of the run-up heights along the Sendai Plain using GPS measurement instruments under the organization of the Joint Survey Group. This report describes our survey results of the run-up heights and discusses variation of the run-up heights in relation to the local topography. We also tested whether numerical modeling for the tsunami inundation can reproduce the ground truth. 


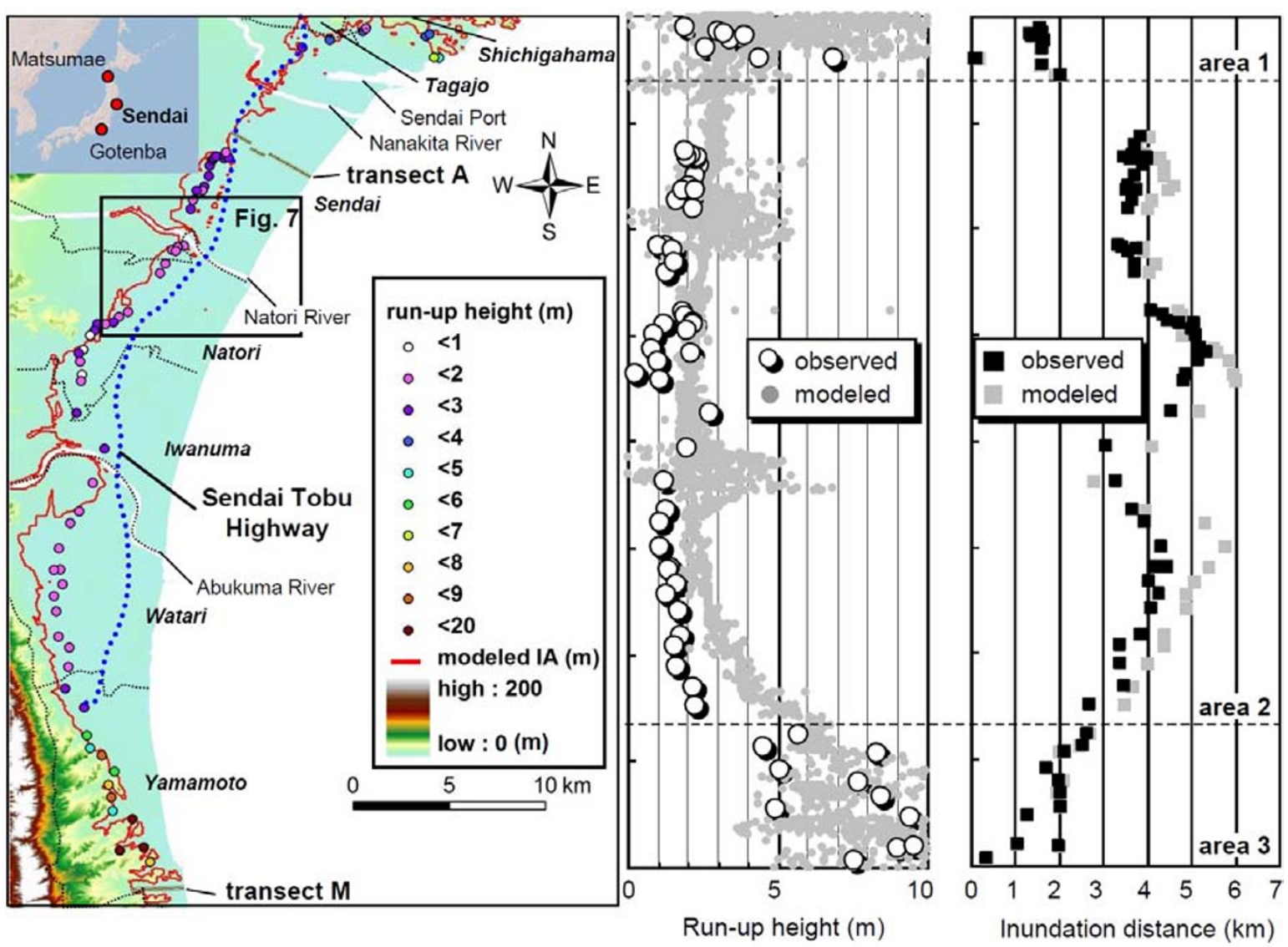

Fig. 1. Measured and modeled run up heights $(\mathrm{m})$ and inundation distances $(\mathrm{km})$ at the studied area. IA: inundation area.

\section{Study Area}

The Sendai Plain, in a broad sense, has a $50-\mathrm{km}$ stretch of coastline, which extends from Sendai city at the northern margin to Yamamoto town at the southern margin (Fig. 1). The plain is segmentalized into northern, central, and southern parts, by the Natori and Abukuma rivers. The plain reaches its maximum width of $10 \mathrm{~km}$ in the central part, which is bordered by Abukuma and Natori rivers. The width of the plain becomes narrow toward its southern margin. The elevation along the west margin of the plain is between 5 and $10 \mathrm{~m}$, although most of the plain is less than $5 \mathrm{~m}$ in elevation. The inclination of the plain becomes steep in the southward part closer to the ocean.

The natural parts of the plain, which has a marine and fluvial origin during the last 25,000 years, are characterized by beach ridges, back marshes, and natural levees. The beach ridges are actually sand dunes, which have developed parallel to the present coastline and paleo-coastlines (Matsumoto, 1985), and which have slightly higher elevation than surrounding areas. Formed by sea-level fluctuations during the late Holocene, the beach ridges have four recognizable rows. Each is numbered as I, I', II, and III from the inland to the coast (Matsumoto, 1984). In the southern part of the plain, the beach ridges are better developed, and the width of each beach ridge is wider than the northern part (Ito, 2006). In addition, the beach ridges have higher elevations in the southern Sendai Plain than in the northern part. The formation ages of beach ridges I, I', II, and III have been dated respectively at 5,000-4,500 yr
BP, 3,100-3,000 yr BP, 2,800-1,600 yr BP, and newer than 1,000-700 yr BP. The average rate of seaward migration of the coastline was estimated at $0.6 \mathrm{~m} / \mathrm{yr}$ in the northern part and $1.2 \mathrm{~m} / \mathrm{yr}$ in the southern part during the last 5,000 years (Ito, 2006). The back marshes, including trace lagoons, developed in the lowlands between and behind the beach ridges in the plain. Natural levees formed along the old river channels. They were formed and remain because of the meandering of the two rivers.

A northward-directed coastal current is dominant in Sendai Bay. The main source of beach material is sediment that originated from the Abukuma and Natori rivers, and partly from the cliff coasts of Joban Coast further south. At present, sediment transport by the coastal current is segmentalized by guide walls that have been constructed at the river mouths and fishery harbors. Because of modern development of dams in the upstream of each river and these coastal structures, significant regression and progression of the coastline, which reaches around several meters per year, has been observed during the last 20 years (Tohoku Regional Bureau, 2000).

In general, the study area includes the beach, with up to $4 \mathrm{~m}$ high coastal dune ridges covered with pine forest and low-lying rice paddy fields at sea level. Offshore and onshore wave breakers (5.2-7.2 $\mathrm{m}$ in height for onshore wave breaker) were settled in several places for maintaining the beach sand and to protect it from storm wave impact. The Sendai Tobu Highway, the embankment of which is approximately $10 \mathrm{~m}$ high, runs north-south at approximately $2.5-$ 


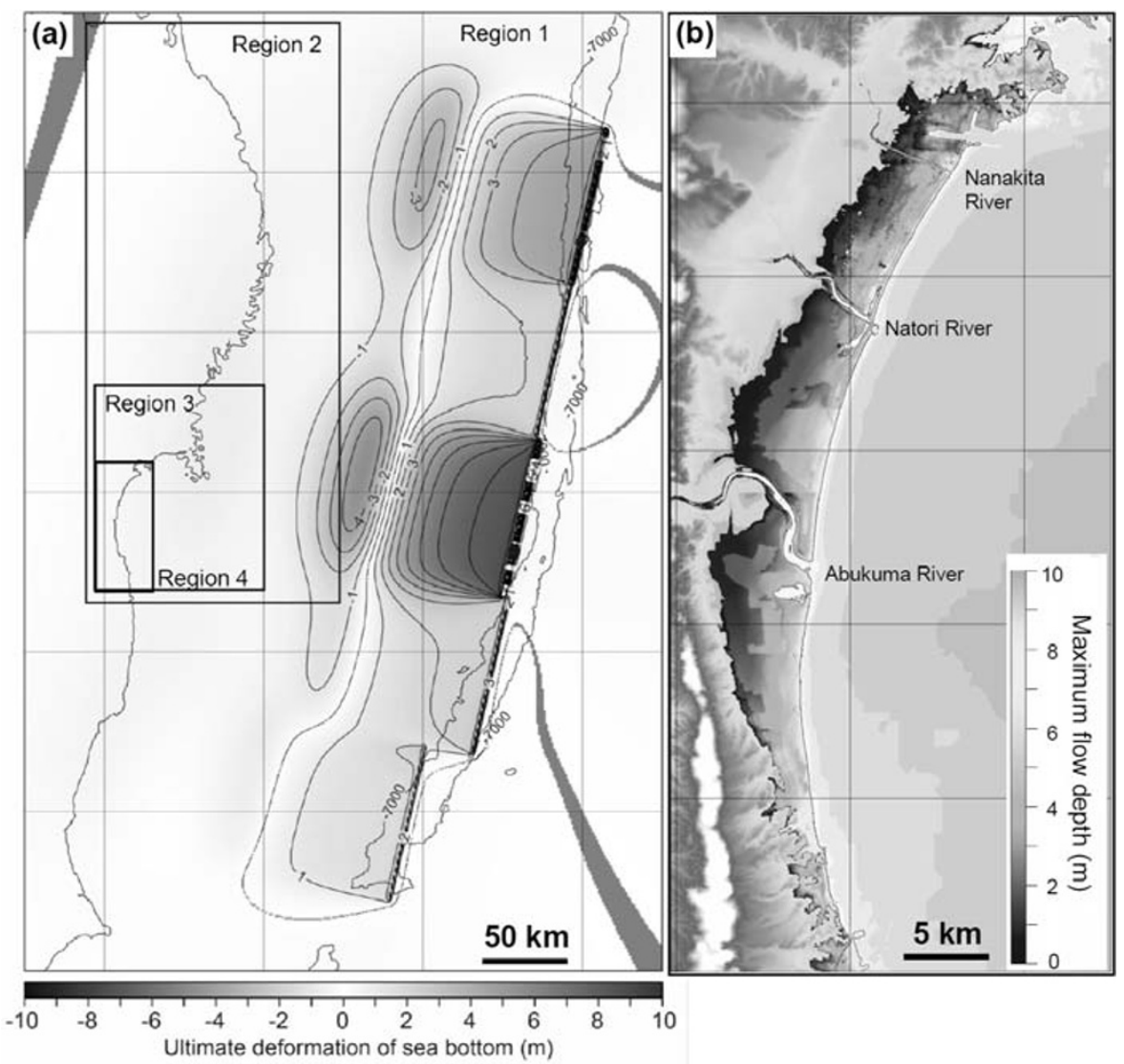

Fig. 2. (a) Computational domain for the model of tsunami propagation and run-up to Sendai Plain and ultimate sea-bottom deformation as a wave source of the Tohoku-oki tsunami (Imamura et al., 2011). The distribution of the sea-bottom deformation was calculated based on Okada (1985). (b) Modeled flow depth (m) over the study area.

$4.5 \mathrm{~km}$ from the shoreline (Fig. 1). The highway embankments have intermittent underpasses.

\section{Methods}

\subsection{Field measurements}

Field surveys were conducted during April 2-4, 2011, the earliest timing to conduct the survey after rescue efforts and life safety issues had been resolved to most of the tsunamiaffected area residents. Figure 1 portrays the survey area at the Sendai Plain from Tagajo to Yamamoto, extending $40 \mathrm{~km}$ north-south. Based on the field investigation, we first identified the inundation limits based on the tsunami traces and estimated the approximate inundation distances perpendicular to the shoreline. Then we measured the absolute elevations (run-up heights) at 69 points using GPS measurement instruments (Promark 3; Ashtech) of average $0.5-2 \mathrm{~km}$ interval. Basis of the elevation data is Tokyo Peil (T.P.).

For measuring the absolute elevations at the Sendai Plain using GPS instruments, it is noteworthy that the adjacent electric reference points (GPS base station) were also moved by crustal deformation of the earthquake on March 11, 2011. In fact, the electric measurement point at Yamoto, $30 \mathrm{~km}$ northeast from Sendai, was displaced horizontally approx. $4 \mathrm{~m}$ eastward and subsided approx. $50 \mathrm{~cm}$. Moreover, they were shut down until April 8, 2011. Therefore, it was necessary to refer the electric reference points that were distant from the affected area, where crustal displace- ment was minimal. To do so, we set a Proflex 500 as the base site, which can refer to electric points within $500 \mathrm{~km}$, at the roof of the highest building at Tohoku University (approx. $160 \mathrm{~m}$ higher than T.P.) and referenced the electric reference points at Matsumae in Hokkaido prefecture and Gotenba in Shizuoka prefecture (approx. $350 \mathrm{~km}$ from Sendai) (Fig. 1). At these electric reference points, no significant vertical crustal movement was recorded. Therefore, run-up heights can be measured accurately.

However, approx. $20 \mathrm{~cm}$ horizontal movement occurred at the Matsumae and Gotenba electric reference points. Nevertheless, considering that the major objective of this research is the highly accurate measurement of run-up heights, we neglected the effects of the horizontal crustal movements because the movements were less than the error to determine the tsunami inundation limit during the field survey, which should have error of less than a few meters.

The GPS rovers (Promark3) in the field were set at the inundation limit and measured up to the observation ranges from the location of the base site of the Proflex500. It took approximately 5-20 min to measure a single point, depending on the satellite condition. Based on this scheme, we were able to measure the run-up heights promptly and accurately (approx. $\pm 20 \mathrm{~cm}$ error for elevation).

\subsection{Numerical modeling}

To simulate the tsunami propagation in the open sea, we used a nonlinear equation to describe a shallow-water wave and to simulate tsunami propagation in the coastal zone 
Table 1. Field measurement data at all points. All data represent the run-up heights (m).

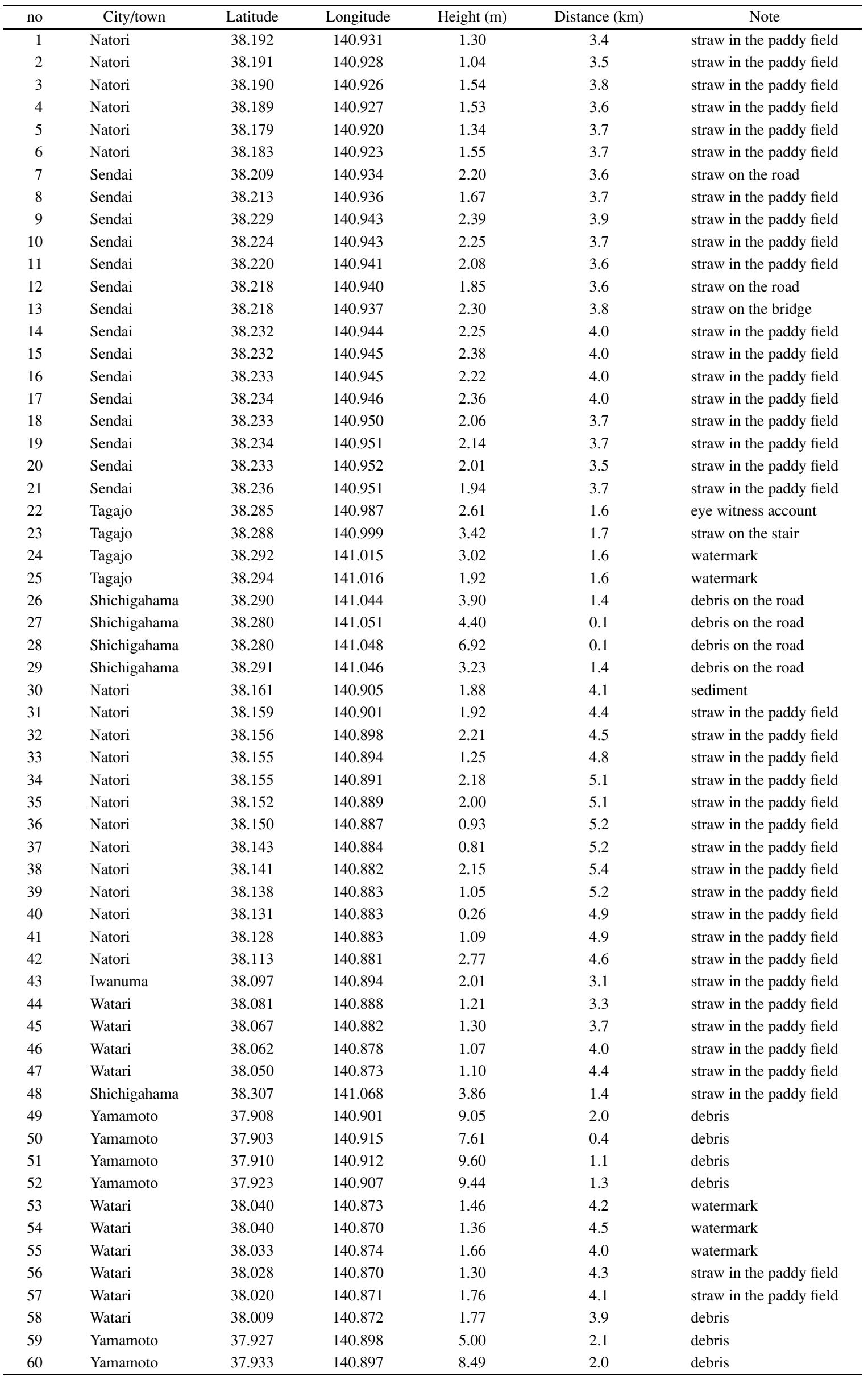


Table 1. (continued).

\begin{tabular}{|c|c|c|c|c|c|c|}
\hline no & City/town & Latitude & Longitude & Height (m) & Distance $(\mathrm{km})$ & Note \\
\hline 61 & Yamamoto & 37.939 & 140.896 & 7.75 & 2.0 & debris \\
\hline 62 & Yamamoto & 37.945 & 140.899 & 5.07 & 1.7 & debris \\
\hline 63 & Yamamoto & 37.962 & 140.886 & 5.72 & 2.7 & straw in the paddy field \\
\hline 64 & Yamamoto & 37.956 & 140.887 & 4.52 & 2.6 & straw in the paddy field \\
\hline 65 & Yamamoto & 37.953 & 140.893 & 8.32 & 2.1 & straw in the paddy field \\
\hline 66 & Yamamoto & 37.975 & 140.884 & 2.27 & 2.7 & straw in the paddy field \\
\hline 67 & Yamamoto & 37.984 & 140.876 & 2.22 & 3.5 & straw in the paddy field \\
\hline 68 & Yamamoto & 37.994 & 140.877 & 1.66 & 3.4 & straw in the paddy field \\
\hline 69 & Yamamoto & 38.004 & 140.877 & 1.61 & 3.4 & straw in the paddy field \\
\hline
\end{tabular}

and inundation on land using a Cartesian coordinate system (Goto et al., 1997), with allowance made for variable bottom friction (Kotani et al., 1998; Kaiser et al., 2011). The governing equations are described as follows.

$$
\begin{aligned}
& \frac{\partial \eta}{\partial t}+\frac{\partial M}{\partial x}+\frac{\partial N}{\partial y}=0 \\
& \frac{\partial M}{\partial t}+\frac{\partial}{\partial x}\left(\frac{M^{2}}{D}\right)+\frac{\partial}{\partial y}\left(\frac{M N}{D}\right) \\
& \quad+g D \frac{\partial \eta}{\partial x}+\frac{g n^{2}}{D^{7 / 3}} M \sqrt{M^{2}+N^{2}}=0 \\
& \frac{\partial N}{\partial t}+\frac{\partial}{\partial x}\left(\frac{M N}{D}\right)+\frac{\partial}{\partial y}\left(\frac{N^{2}}{D}\right) \\
& \quad+g D \frac{\partial \eta}{\partial y}+\frac{g n^{2}}{D^{7 / 3}} N \sqrt{M^{2}+N^{2}}=0 .
\end{aligned}
$$

In those equations, $\eta$ is the elevation of the water surface from the still water level, $M$ and $N$ respectively denote discharge fluxes in the $x$-direction and $y$-direction, $D$ signifies the total water depth $(=h+\eta)$, and $n$ represents Manning's roughness. The staggered leap-frog method, a finitedifference method, was used to solve equations numerically (Goto et al., 1997). The roughness coefficient at each grid cell is set according to the land condition based on findings by Kotani et al. (1998) and Kaiser et al. (2011). In this study, a roughness coefficient of 0.025 was assigned for water, 0.03 for bare ground and grassland, 0.04 for control forest and 0.05 for residential area.

We assumed a composite fault model proposed by Imamura et al. (2011) as the source for the tsunami (Fig. 2(a)). Although this model is a tentative one, it reproduces the tidal record well, in addition to the measured run-up height and local subsidence at the Pacific coast of Japan (Imamura et al., 2011). We constructed a nested grid system across a wide area (regions 1-3) to the study area (region 4) (Fig. 2(a)). Spatial grid sizes of respective regions were 1,215 $\mathrm{m}$ for region $1,405 \mathrm{~m}$ for region $2,135 \mathrm{~m}$ for region 3 , and $45 \mathrm{~m}$ for region 4 . The calculation time is $180 \mathrm{~min}$ after the tsunami generation. The numerical modeling used public bathymetric and topographic datasets provided by the Central Disaster Prevention Council, Japan, and the Tohoku Regional Bureau, Ministry of Land, Infrastructure and Transport. The Sendai Tobu Highway is not well incorporated in the topographic data in region 4 because it is not reproducible in the $45 \mathrm{~m}$ grid size.

\section{Results}

Tsunami inundation in the Sendai Plain is generally classified into areas of three types from north to south (Fig. 1, Table 1): (1) inundation in the urban city at the Tagajo and Shichigahama near the Sendai Port (area 1); (2) inundation in the very wide and flat plain at Sendai, Natori, Iwanuma, and Watari plus north of Yamamoto (area 2), and (3) inundation in the narrow plain at Yamamoto (area 3).

\subsection{Area 1}

Tagajo and Shichigahama are located north of the Sendai megacity close to the Sendai Port (Fig. 1). The area is densely populated. Therefore, the tsunami inundation process was very complex because artificial objects such as buildings, infrastructure, and port functions affected the tsunami inundation. Most tsunami traces at the inundation limit were marked by watermarks on the buildings (Fig. 3(a)) and concentrations of small debris. The run-up heights and inundation distances in the densely populated area were, respectively, 2-4 m and 1.4-1.7 km (Fig. 1). However, the run-up height and inundation distance were up to $6.9 \mathrm{~m}$ and $0.1 \mathrm{~km}$, respectively at places where a steep slope was located behind the small port (Fig. 3(b)).

\subsection{Area 2}

At most places in this area, tsunami damage was extremely severe near the coastal zone. In fact, houses and coastal trees were destroyed extensively and much debris was deposited elsewhere (Fig. 4(a)). According to the TETJSG (2011), tsunami flow heights (inundation heights) near the coastal zone in this area were ca. $15 \mathrm{~m}$.

The tsunami flow depths decrease continuously landward to nearly $0 \mathrm{~m}$ (e.g. Goto et al., 2011a). The Sendai Tobu Highway played an important role in protecting the area from further tsunami inundation, especially from Sendai to Iwanuma, where the highway is located up to $4.5 \mathrm{~km}$ from the shoreline (e.g. Sugawara et al., 2012). In fact, much floating debris was stopped at the eastern (seaward) side of the highway because of the 10-m high embankment (Fig. 5(a)). Although major tsunami inundation generally stopped at the highway from Sendai to Iwanuma, tsunami inundation reached far beyond the highway at Watari, where the highway was located up to $2.5 \mathrm{~km}$ from the shoreline. Moreover, even in the Sendai to Iwanuma area, the tsunami inundation was not fully halted at the highway because elevated bridges and drainage channels allowed the tsunami to flow underneath the highway (Fig. 5(b)). Consequently, the tsunami inundated up to $5.4 \mathrm{~km}$ further west from the highway from the shoreline (Figs. 6(a), 7). 

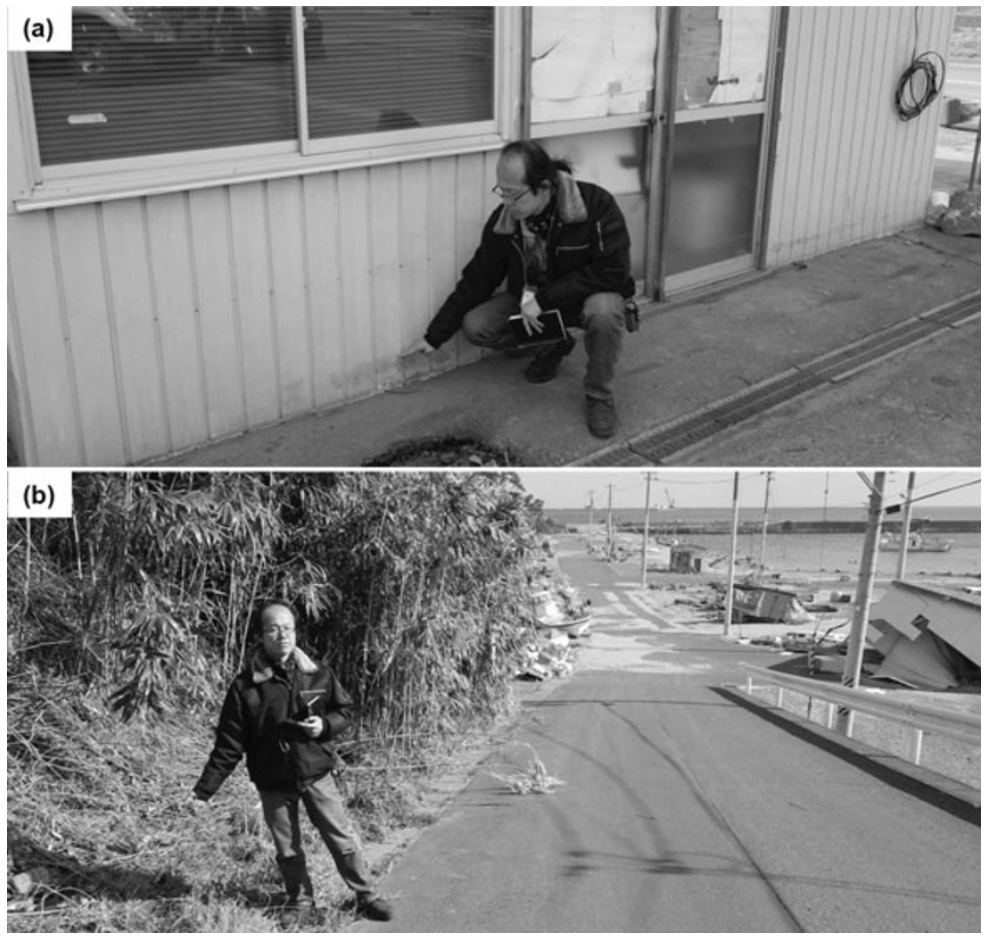

Fig. 3. (a) Watermark on the wall of building at Tagajo (no. 24 in Table 1). (b) Tsunami traces at the inundation limit at Shichigahama (no. 27).
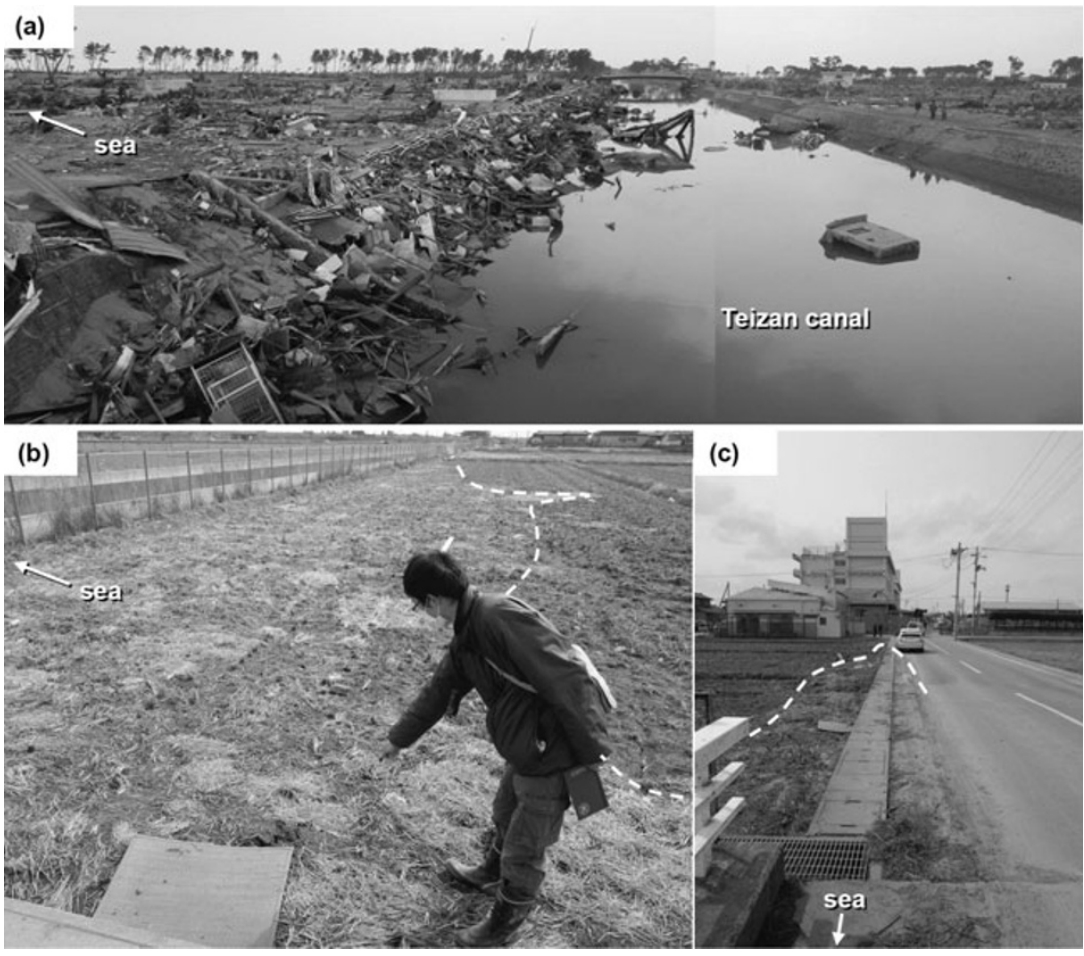

Fig. 4. (a) Much debris deposited close to the coastal zone near the Teizan canal of approximately $0.4 \mathrm{~km}$ from the shoreline at Arahama area in Sendai. (b) Tsunami traces at the inundation limit at Sendai (no. 8). (c) Tsunami inundated further inland through the street gutter (no. 8).

Beyond the highway, tsunami traces are subtle and mostly characterized by the concentration of paddy straw and light debris (Fig. 4(b)). No severe damage was observed near the inundation limit. It was also observed that the paddy straw was deposited close to the artificial channels and street gutters (Fig. 4(c)). This observation suggests that the tsunami inundation extended further inland through such low water passages. The tsunami inundation sometimes stopped in front of local undulations such as rice paddy dykes.

Run-up heights in this area were almost identical, as high as ca. $3 \mathrm{~m}$, whereas inundation distances were $3.1-5.4 \mathrm{~km}$ (Fig. 1). 

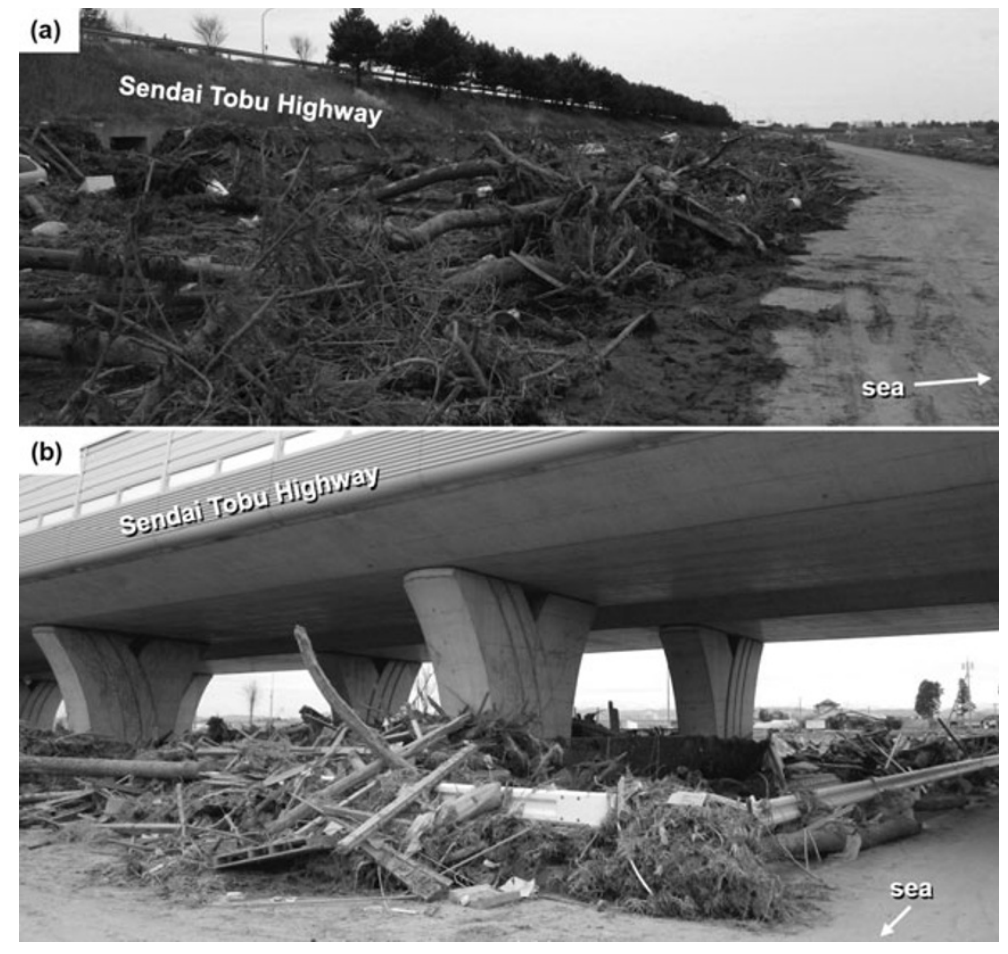

Fig. 5. (a) Seaward (east) side of the Sendai Tobu Highway at Sendai. The embankment is $10 \mathrm{~m}$ high. Much debris was deposited in front of it. (b) Bridge of the highway. Tsunami could have flowed through such an underpass further inland.
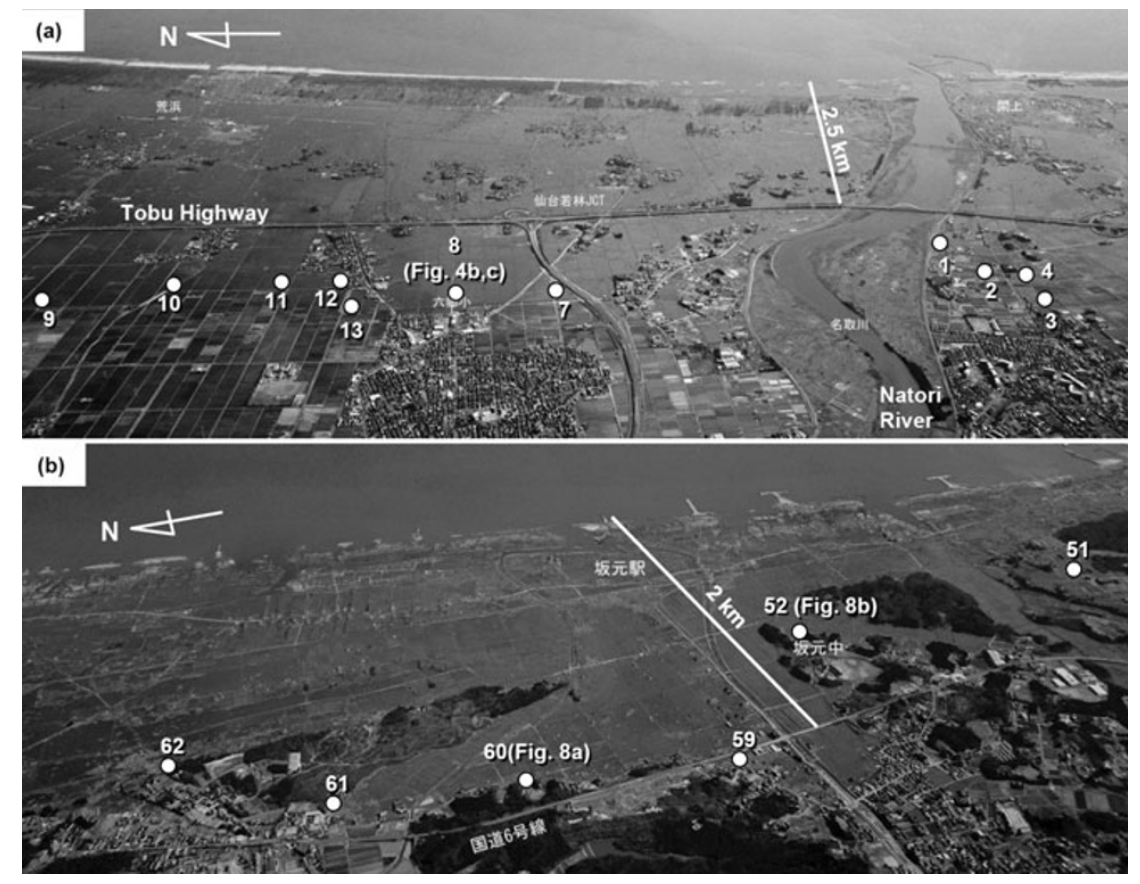

Fig. 6. Aerial photographs taken at (a) Sendai to Natori close to the Natori River and (b) near Sakamoto Station in Yamamoto (provided by Asia Air Survey Co. Ltd.). Both photographs were taken on March 13, 2011. Numbers on the photo correspond to those in Table 1.

\subsection{Area 3}

Different from the flat and wide plain in area 2 , area 3 is characterized by the narrower and steep plain. The inundation limit is generally at the bottom of the hill (Fig. 6(b)), probably because the plain is narrow and because tsunami inundation was forced to stop at the steep slope of the hill. Moreover, the inundation limit line was observed clearly because of the concentration of much large floating de- bris even at the inundation limit (Fig. 8). Tsunami run-up heights and inundation distances are, respectively, highly variable: $9.6 \mathrm{~m}$ at $0.4 \mathrm{~km}$ to $1.6 \mathrm{~m}$ at $3.5 \mathrm{~km}$.

\subsection{Modeled run-up heights and inundation distances}

Figure 2(b) shows the modeled maximum flow depth over the study area. The figure shows maximum flow depths near the shoreline as nearly $10 \mathrm{~m}$, which are consistent with the measured values (TETJSG, 2011). The figure shows 


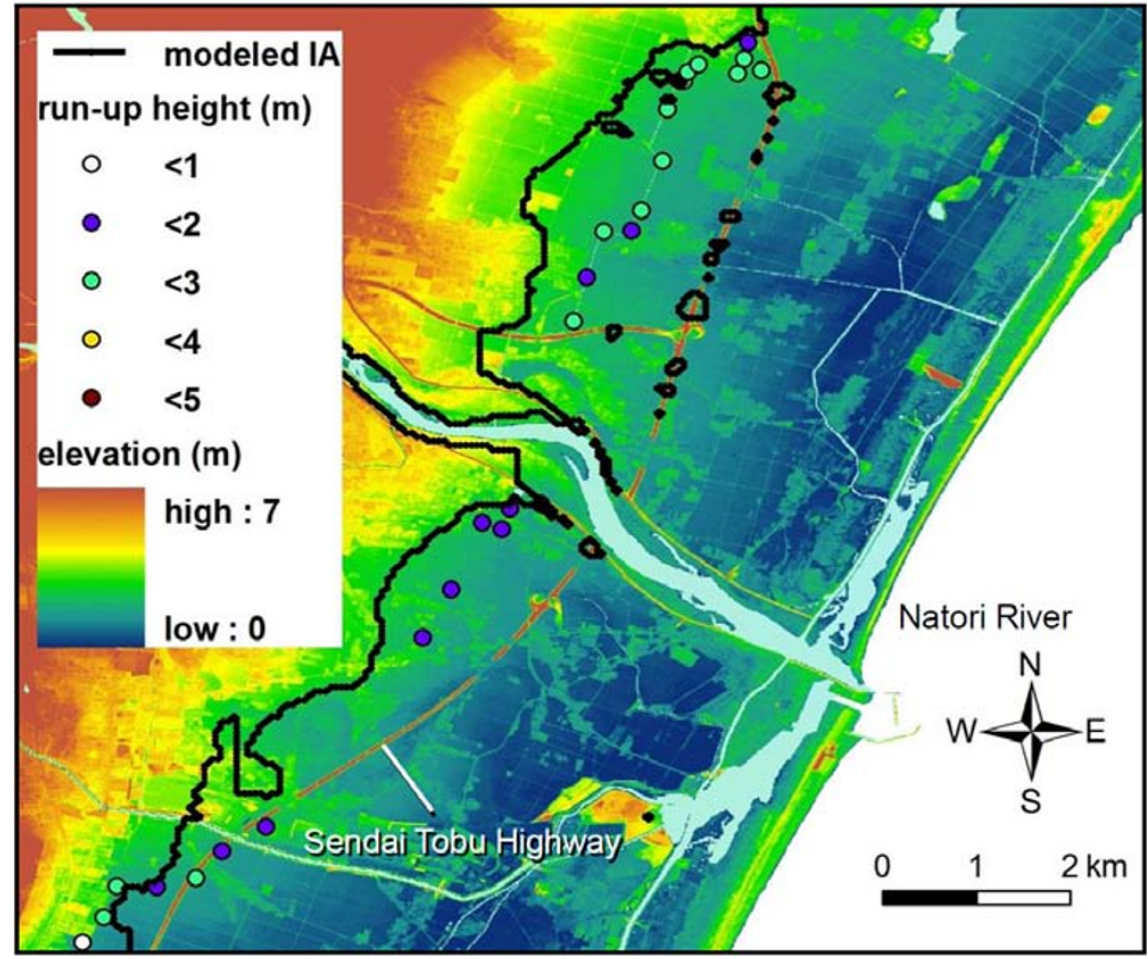

Fig. 7. Measured and modeled tsunami inundation distance and run-up heights $(\mathrm{m})$ shown on the $5 \mathrm{~m}$ DEM data before the tsunami. IA, inundation area.
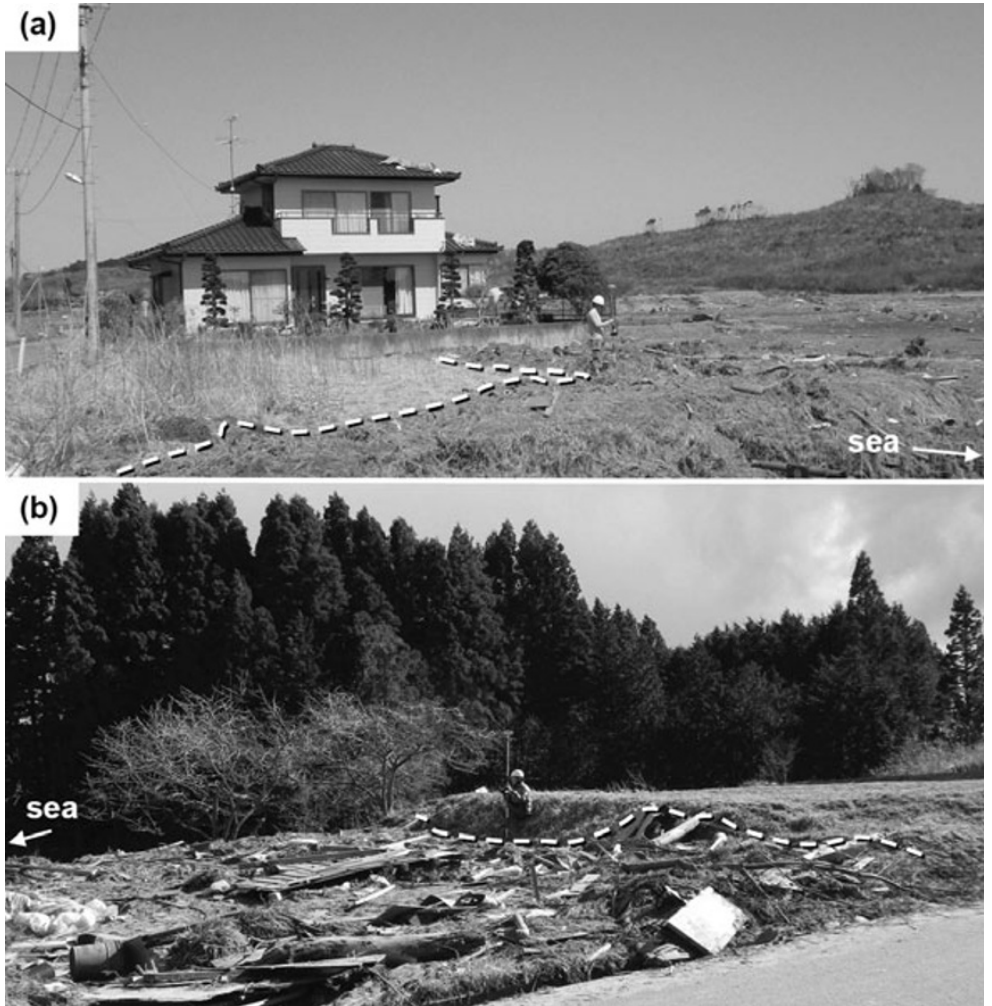

Fig. 8. Inundation limits at (a) no. 60 and (b) no. 52. The clear limit lines are notably different from around Sendai (Fig. 4(b)).

further that the narrower plain at the south of the Sendai Plain was fully inundated but a wider plain area was characterized by partial inundation up to $6 \mathrm{~km}$. In addition, Fig. 1 shows modeled run-up heights and inundation distances over the study area. Overall, the modeled run-up heights and inundation distances are consistent with the measured ones, especially in areas 1 and 3. However, the modeled run-up heights and inundation distances are overestimated for area 2. 


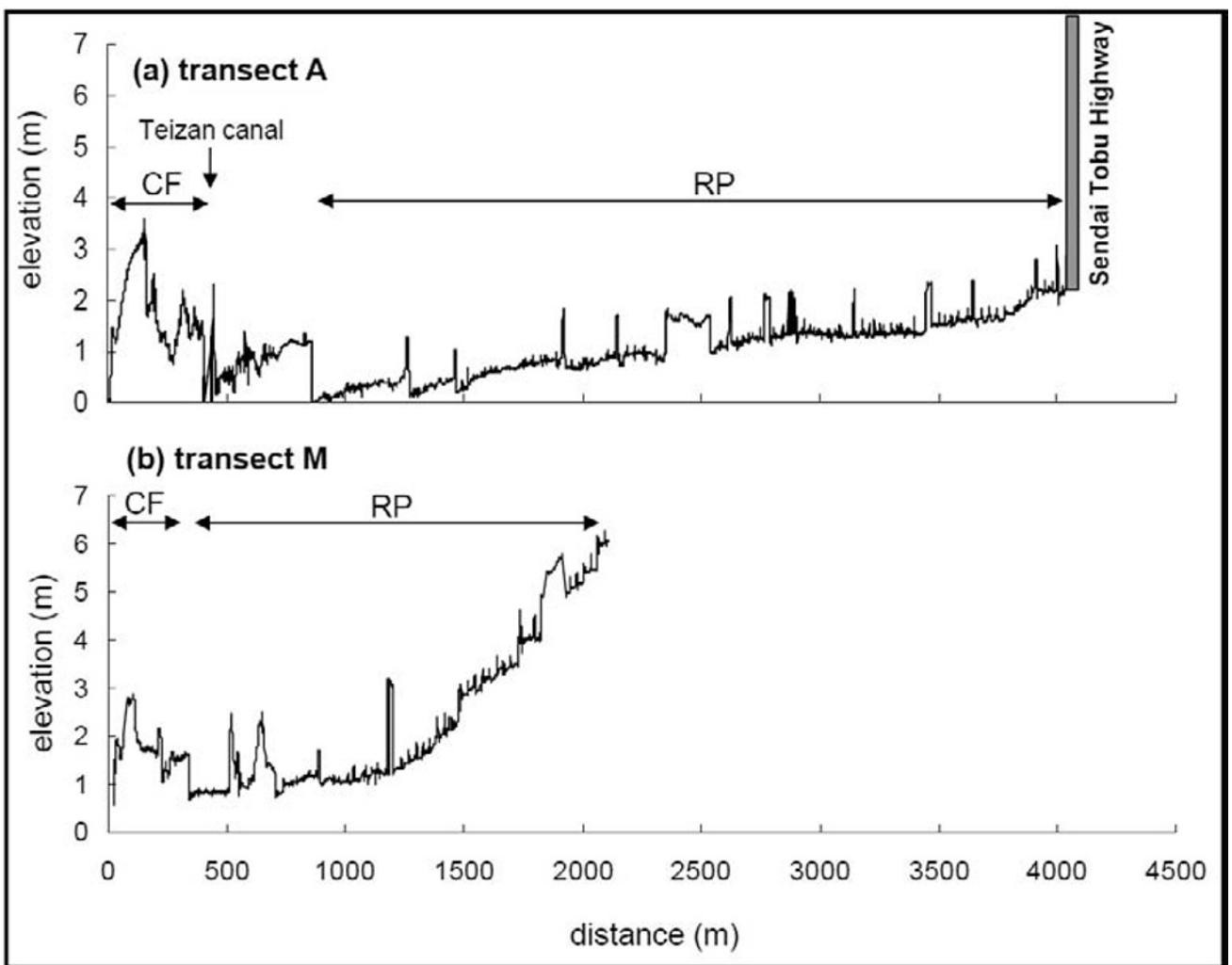

Fig. 9. Topographic profiles along transects A and M in Fig. 1 (modified after Abe et al., 2011; Goto et al., 2011b). CF, coastal forest; RP, rice paddy.

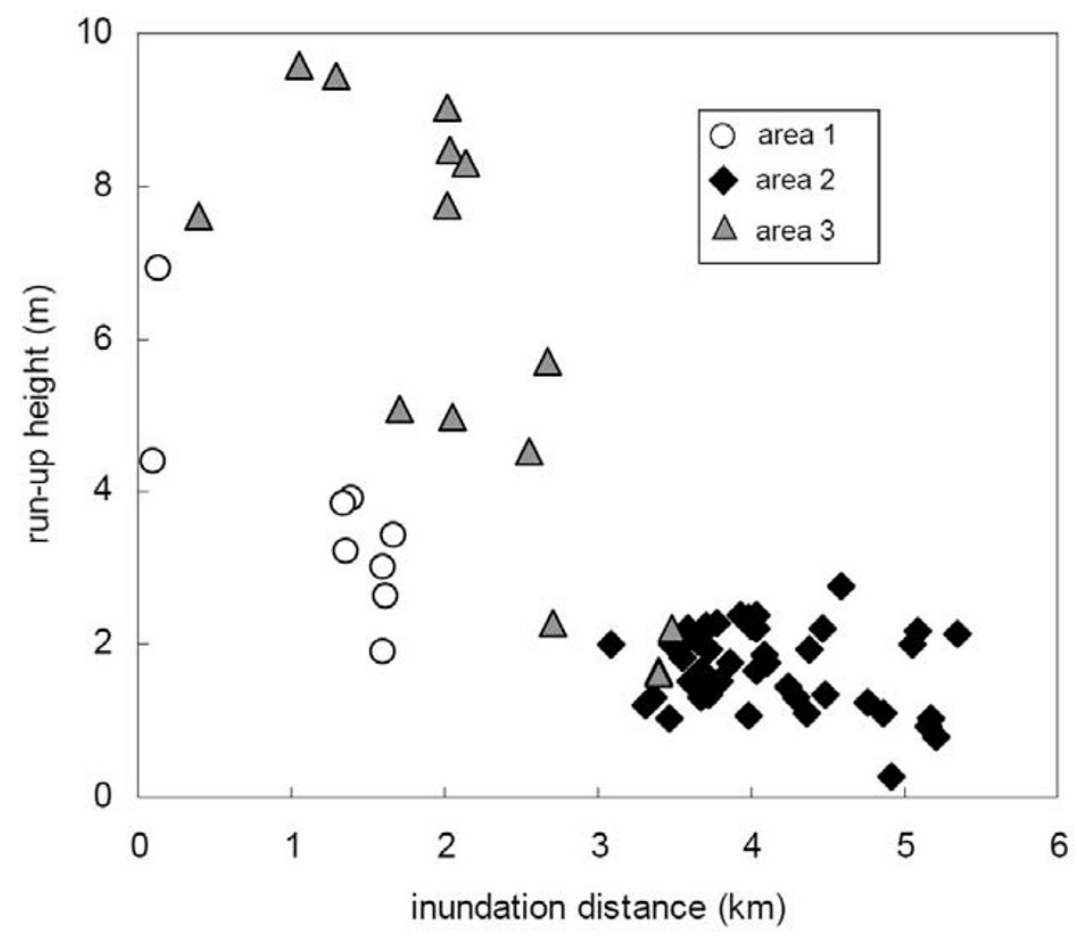

Fig. 10. Measured inundation distance ( $\mathrm{km})$ vs. run-up heights $(\mathrm{m})$ at the studied sites.

\section{Discussion}

The tsunami inundation process at the Sendai Plain is generally controlled both by the local topography and by land use. Figure 9 presents a comparison of the crosssectional topographic profiles along transects in Sendai in area 2 (Transect A) and in Yamamoto in area 3 (Transect M) (see Fig. 1 for locations) as measured by Abe et al. (2011) and Goto et al. (2011b). Along transect A in Sendai, the topography is characterized by the remarkably flat surface behind the sand dune (Fig. 9(a)), although it is characterized by steep topography along transect $\mathrm{M}$ in Yamamoto (Fig. 9(b)). 
In area 2, the inundation limit is also affected by the local topography as portrayed in Fig. 7, which shows that the tsunami waves generally stopped at around 2-3 $\mathrm{m}$ high elevation. In area 2 , the tsunami traces near the inundation limit line were subtle and were sometimes difficult to identify even a few weeks after the tsunami, probably because the tsunami flow was weak and insufficient to transport large debris; only paddy straw and light debris were transported and deposited around the limit line.

In contrast, the topography in area 3 is characterized by steep slope inclination $(0.3 \%$, Abe et al., 2011). In this area, large debris was deposited to a noticeable degree, even at the inundation limit (Fig. 8) and tsunami flow might have been forced to stop in front of the topographic high.

In addition to the topography, land use is important to control the inundation limit. In fact, the inundation limit at area 1 was complex because buildings and infrastructure as well as the rivers affected the tsunami inundation process. Moreover, the Sendai Tobu Highway played an important role in determining the inundation limit line, which in turn suggests that the highway partly acted as protection against the tsunami inundation (Sugawara et al., 2012).

A negative correlation exists between the inundation distances and run-up heights (Fig. 10) probably because both are mainly controlled by the topography. The inundation distance was short and the run-up height was high at the steep topographic setting, although they were long and low in the flat plain area. It is important to note that area 1 (densely populated area) was characterized by a lower runup height and shorter inundation distance than in other areas (Fig. 10), probably because the artificial objects reduced the tsunami energy. Consequently, tsunami inundation was stopped at the place with lower height and shorter distance from the shoreline.

The numerical calculation generally reproduced the overall trend of the measured run-up heights and inundation area well at areas 1 and 3 (Fig. 1), probably because the run-up heights and inundation area in these areas are generally controlled by the local topography. However, these are generally overestimated in numerical calculations in area 2 , probably because the spatial grid size $(45 \mathrm{~m})$ is insufficient to reproduce the local land use, especially the Sendai Tobu Highway, which is expected to have acted to reduce the tsunami energy greatly.

\section{Conclusions and Implications for Future Anal- yses}

One important result of our study is that we established a scheme of quick and accurate measurement of the run-up heights at the remarkably long tsunami inundation area using GPS instruments. By adopting this scheme, we were able to measure an average of 23 points each day, while standard measurement methods (e.g., leveling and total station), which measure the elevation from the shoreline, might have limited measurements to only $1-2$ points per day with larger error than our measurements. Considering that the subtle tsunami traces at the inundation limits disappeared quickly (even in early April, traces are not recognizable at few places), our measurement scheme of the run-up heights is expected to be effective.
The results showed extensively long inundations (ca. $5.4 \mathrm{~km}$ ) and low run-up heights (ca. $3 \mathrm{~m}$ ) at the wide and flat plain in area 2, and highly diverse run-up heights and inundation distances at area 3 . In urban area 1 , tsunami inundation is more complex. Both topography and land-use conditions affect the run-up heights and inundation distances. A large difference of the tsunami traces exists at the inundation limit along the long inundation/low run-up height area (area 2) and short inundation/high run-up height area (areas 1 and 3). The former is characterized by subtle traces such as the minor redistribution of paddy straw, whereas the latter is characterized by the concentration of much floating debris.

Our observations at Sendai Plain can be regarded as an important ground truth for interpreting the results of future analyses using aerial/satellite imageries and numerical modeling. In fact, interpretation of aerial and satellite imageries might underestimate the maximum inundation area, especially at area 2 , because the subtle traces of the tsunami inundation were difficult to identify even in the field. However, numerical modeling cannot reproduce the minor inundation from the highway because the topographic data for the modeling are usually rough. Moreover, the small channels and street gutters, which played an important role in local inundation beyond the highway, are not reproducible in the modeling without meter-scale high resolution topographic data.

Our study is critically important to elucidate the limitations of analyses of aerial/satellite images and numerical modeling to elucidate the inundation process of a remarkably flat and wide plain, as with the Sendai Plain.

Acknowledgments. This research was supported by a research grant from Tohoku University for an emergency field survey following the 2011 Tohoku-oki tsunami. We thank F. Imamura, S. Koshimura, Y. Nishikawa, A. Takezoe, H. Shibuya, and T. Matsui for their support of the study. We also thank T. Furumura, Y. Namegaya, and R. Wilson for their valuable suggestions and comments.

\section{References}

Abe, T., K. Goto, and D. Sugawara, Relationship between the maximum landward extent of the deposit and inundation limit of the 2011 Tohokuoki tsunami, AGU Fall Meeting 2011, NH11A-1338, 2011.

Fujii, F., K. Satake, S. Sakai, M. Shinohara, and T. Kanazawa, Tsunami source of the 2011 off the Pacific coast of Tohoku Earthquake, Earth Planets Space, 63, 815-820, 2011.

Geospatial Information Authority of Japan, Overall condition of the tsunami inundation area (1:25,000 map), http://www.gsi.go.jp/kikaku/kikaku40014.html, 2011.

Goto, C., Y. Ogawa, N. Shuto, and F. Imamura, IUGG/IOC Time Project, Numerical method of tsunami simulation with the Leap-Frog scheme, IOC Manuals and Guides, UNESCO, Paris, 130 p., 1997.

Goto, K., C. Chagué-Goff, S. Fujino, J. Goff, B. Jaffe, Y. Nishimura, B. Richmond, D. Sugawara, W. Szczuciński, D. R. Tappin, R. Witter, and E. Yulianto, New insights of tsunami hazard from the 2011 Tohoku-oki event, Mar. Geol., 290, 46-50, 2011a.

Goto, K., D. Sugawara, T. Abe, T. Haraguchi, and S. Fujino, Rapid beach recovery after the 2011 Tohoku-Oki tsunami at Sendai Plain, Japan, AGU Fall Meeting 2011, NH11A-1336, 2011 b.

Hayashi, Y., H. Tsushima, K. Hirata, K. Kimura, and K. Maeda, Tsunami source area of the 2011 off the Pacific coast of Tohoku Earthquake determined from tsunami arrival times at offshore observation stations, Earth Planets Space, 63, 809-813, 2011.

Hirose, F., K. Miyaoka, N. Hayashimoto, T. Yamazaki, and M. Nakamura, Outline of the 2011 off the Pacific coast of Tohoku Earthquake 
$\left(M_{\mathrm{w}}\right.$ 9.0)—Seismicity: Foreshocks, mainshock, aftershocks, and induced activity-, Earth Planets Space, 63, 513-518, 2011.

Imamura, F., S. Koshimura, T. Oie, Y. Mabuchi, and Y. Murashima, Tsunami simulation for the 2011 off the Pacific coast of Tohoku Earthquake (Tohoku University model ver. 1.0), 12 pp., 2011.

Ito, A., Marine regression during the historical time in Sendai Coastal Plain, Northeastern Japan, Bulletin of the Faculty of Education, Kagoshima University, Studies in Education, 57, 1-8, 2006 (in Japanese with English abstract).

Kaiser, G., L. Scheele, A. Kortenhaus, F. Lovholt, H. Romer, and S. Leschka, The influence of land cover roughness on the results of high resolution tsunami inundation modeling, Nat. Haz. Earth Syst. Sci., 11, 2521-2540, 2011.

Kotani, M., F. Imamura, and N. Shuto, Tsunami run-up simulation and damage estimation using GIS, P. Coast. Eng., JSCE, 45, 356-360, 1998 (in Japanese).

Maeda, T., T. Furumura, S. Sakai, and M. Shinohara, Significant tsunami observed at ocean-bottom pressure gauges during the 2011 off the $\mathrm{Pa}$ cific coast of Tohoku Earthquake, Earth Planets Space, 63, 803-808, 2011.

Matsumoto, H., Beach ridges in coastal plains and late Holocene sea-level fluctuations, Geogr. Rev., 57, 730-738, 1984 (in Japanese with English Abstract).
Matsumoto, H., Beach ridge ranges and the holocene sea level fluctuations on alluvial coastal plains, Northeast Japan, Sci. Rep. Tohoku Univ., 7th series (Geography), 35, 15-46, 1985.

Mori, N., T. Takahashi, T. Yasuda, and H. Yanagisawa, Survey of 2011 Tohoku earthquake tsunami inundation and run-up, Geophys. Res. Lett., 38, L00G14, 2011.

Okada, Y., Surface deformation due to shear and tensile faults in a halfspace, Bull. Seismol. Soc. Am., 75, 1135-1154, 1985.

Sugawara, D., F. Imamura, K. Goto, H. Matsumoto, and K. Minoura, The 2011 Tohoku-oki earthquake tsunami: Similarities and differences between the 869 Jogan tsunami on the Sendai Plain, Pure Appl. Geophys., doi:10.1007/s00024-012-0460-1, 2012 (published online).

The 2011 Tohoku Earthquake Tsunami Joint Survey Group, Nationwide field survey of the 2011 off the Pacific coast of Tohoku Earthquake Tsunami, J. Japan Soc. Civil Eng., Ser. B2, 67, 63-66, 2011.

Tohoku Regional Bureau, Ministry of Land, Infrastructure and Transport, Miyagi Prefecture Public Works Department, Report of Coastal Engineering Research Committee of Sendai Bay, 73 p., 2000.

K. Goto (e-mail: kgoto@perc.it-chiba.ac.jp), K. Fujima, D. Sugawara, S. Fujino, K. Imai, R. Tsudaka, T. Abe, and T. Haraguchi 